\title{
Prediction of leaf Bloch disease risk in Norwegian spring wheat based on weather factors and host phenology
}

\author{
Anne-Grete Roer Hjelkrem • Andrea Ficke • \\ Unni Abrahamsen • Ingerd Skow Hofgaard • \\ Guro Brodal
}

Accepted: 8 February 2021 / Published online: 17 February 2021

(C) The Author(s) 2021

\begin{abstract}
Leaf blotch diseases (LBD), such as Septoria nodorum bloch (Parastagnospora nodorum), Septoria tritici blotch (Zymoseptoria tritici) and Tan spot (Pyrenophora tritici-repentis) can cause severe yield losses (up to 50\%) in Norwegian spring wheat (Triticum aestivum) and are mainly controlled by fungicide applications. A forecasting model to predict disease risk can be an important tool to optimize disease control. The association between specific weather variables and the development of LBD differs between wheat growth stages. In this study, a mathematical model to estimate phenological development of spring wheat was derived based on sowing date, air temperature and photoperiod. Weather factors associated with LBD severity were then identified for selected phenological growth stages by a correlation study of LBD severity data (17 years). Although information regarding host resistance and previous crop were added to the identified weather factors, two purely weather-based risk prediction models (CART, classification and regression tree algorithm) and one black box model (KNN, based on $\mathrm{K}$ nearest neighbor algorithm) were most accurate to predict moderate to high LBD severity ( $>5 \%$ infection). The predictive accuracy of these models (76-83\%) was compared to that of two existing
\end{abstract}

A.-G. R. Hjelkrem $(\bowtie) \cdot$ U. Abrahamsen

Division of Food Production and Society, Norwegian Institute of Bioeconomy Research (NIBIO), 1431 Ås, Norway

e-mail: anne-grete.hjelkrem@nibio.no

A. Ficke · I. S. Hofgaard - G. Brodal

Division of Biotechnology and Plant Health, Norwegian Institute of Bioeconomy Research (NIBIO), 1431 Ås, Norway models used in Norway and Denmark (60 and 61\% accuracy, respectively). The newly developed models performed better than the existing models, but still had the tendency to overestimate disease risk. Specificity of the new models varied between 49 and $74 \%$ compared to 40 and $37 \%$ for the existing models. These new models are promising decision tools to improve integrated LBD management of spring wheat in Norway.

Keywords Phenological development in wheat . Cereals · Parastagonospora nodorum . Septoria . Zymoseptoria tritici P Pyrenophora tritici-repentis . Disease risk models

\section{Introduction}

Parastagonospora nodorum (also known as Septoria nodorum, Phaeosphaeria nodorum, or Stagonospora nodorum) causal agent of Glume blotch and Septoria nodorum blotch (SNB), Zymoseptoria tritici (also known as Septoria tritici or Mycosphaerella graminicola) causing Septoria tritici blotch (STB) and Pyrenophora tritici-repentis (also known as Drechlsera tritici-repentis), causing Tan spot or Yellow spot (DTR) are major necrotrophic leaf pathogens in wheat (Bergstrom 2010; Shaner 2010; McMullen 2010). These pathogens cause similar symptoms on wheat leaves, e.g. light brown oval to elongated lesions or blotches with yellow margins. As they can co-occur in the same field and on the same leaf, the three leaf diseases are difficult to distinguish with the unaided 
eye and are considered together as the leaf blotch disease (LBD) complex in this study. In Norway, $P$. nodorum is the dominating pathogen in spring wheat, but $Z$. tritici and $P$. tritici-repentis also occur regularly (Ficke et al. 2018a) and need to be considered for effective disease management. The potential for $P$. nodorum to cause significant grain yield and quality losses has been discussed recently (Ficke et al. 2018b). In fungicide trials in Norway, an average yield loss has been found to range from $13 \%$ in a moderately resistant cultivar to $25 \%$ in a susceptible cultivar (Ficke et al. 2016a).

The photosynthetic active tissue area of the flag leaf is considered an important factor in determining grain yield (Simpson 1968; Lupton 1972). King et al. (1983) found a strong relationship between LBD severity on the flag (first) and second leaf at growth stage (GS) 75 (medium milk (Zadoks et al. 1974)) and yield reduction. Assessment of LBD on the last upper two to three leaves at GS 70-77 (water ripe to late milk) have become a standard GS in many countries to evaluate disease severity (Bhathal et al. 2003; King et al. 1983). The reduction of the yield determining area and consequently yield loss from LBD pathogens can vary considerably between years, varieties and locations, making the use of a general management threshold unfeasible. Control of LBD pathogens is based on the use of healthy or fungicide treated seed (for SNB and DTR), tillage and crop rotation, varietal host resistance when available, and fungicide applications (Shipton et al. 1971; Jørgensen and Olsen 2007; Jørgensen et al. 2008). Fungicide applications are only profitable when their application is aligned with the actual need to control a disease and justified by a certain level of expected yield loss. Wiik and Rosenqvist (2010) showed that the mean net return for fungicide use in Swedish winter wheat fields was negative in 10 out of 25 years, and it was less than $12 €$ per ha on average during the period. Routine application of fungicide appears little profitable and should be replaced by reliable disease risk models to guide the farmers decisions and implement integrated pest management (IPM) principles.

Weather conditions in the growing season, tillage, crop rotation and host resistance influence the development of LBD and yield loss. All three LBD pathogens can survive on wheat stubble between growth seasons. Parastagonospora nodorum and Z. tritici produce splash dispersed conidia in pycnidia or ascospores in pseudothecia on wheat debris (Faulkner and Colhoun 1976; Shaw and Royle 1993; Suffert et al. 2011), while
P. tritici-repentis produces wind-dispersed conidia or ascospores from pseudothecia that can infect the young wheat plants (Wright and Sutton 1990). Once infection is established, these polycyclic diseases infect upper layers of the growing wheat plants via conidia. Conditions considered favorable for infections include continuous precipitation or high levels of humidity ( $>90 \%$ ) for several hours (> $4 \mathrm{~h}$ ) (Jeger et al. 1981; Hess and Shaner 1987; Francl 1998). Temperature also plays an important role in LBD development. Severity of DTR was positively correlated with temperature, with an optimum between 18 to $28{ }^{\circ} \mathrm{C}$ depending on the variety used (Da Luz and Bergstrom 1986). Highest STB inoculum production on wheat seedlings has been reported between 18 and $22^{\circ} \mathrm{C}$ during the day (Chungu et al. 2001), and for SNB the latent period was shortest at $23^{\circ} \mathrm{C}$ (Shearer and Zadoks 1972). Wiik and Ewaldz (2009) showed that air temperature and precipitation as monthly means explained more than $50 \%$ of the variation in yield increase due to fungicides and variation in diseases, including LBD on winter wheat in Sweden. Prediction models to estimate risk based on weather factors influencing disease development would be very useful to determine the need for chemical control and the optimal timing of these control measures to avoid redundant use of resources.

By systemizing our knowledge on the effect of these weather factors, a prediction model to estimate risk of disease outbreaks can be constructed. EPISET, a SNB simulation model was developed by Rapilly and Jolivet in 1976 to understand better each stage of pathogen development in relation to precipitation, humidity and temperature (Rapilly and Jolivet 1976). Several disease prediction models exist for $Z$. tritici and/or $P$. nodorum development in winter wheat, based on precipitation (Tyldesley and Thompson 1980; Hansen et al. 1994), and for Z. tritici based on precipitation and air temperature (Coakley et al. 1985; Te Beest et al. 2009), precipitation and relative humidity or precipitation, air temperature and wind speed (Pietravalle et al. 2003). Some of these models additionally require information about when the plant reach stem elongation (Hansen et al. 1994; Te Beest et al. 2009; Pietravalle et al. 2003). De Wolf and Francl (1998) evaluated an empirical $P$. tritici-repentis infection period model for its use in a DTR forecasting system based on temperature, relative humidity, wind speed, wind direction, solar radiation, precipitation, and flat-plate type wetness sensor resistance. Djurle and Yuen (1991) developed a simulation model for $P$. nodorum that was connected to a winter wheat growth model to demonstrate that 
weather conditions were the most important factors for an SNB epidemic in a particular year. However, only a few models are widely used by the farmers and models to predict the risk of all three LBD diseases in spring wheat are absent in the peer reviewed literature.

Hansen et al. (1994) developed a forecasting model to estimate the risk of Septoria development (including SNB and STB) in winter wheat under Danish conditions based on 10 years of field data. The model starts at the beginning of stem elongation (GS 32) and considers sowing date, air temperature and precipitation as inputs to give an estimate of infection risk as output. In this model, a threshold value of $5 \%$ disease severity of total green leaf area at medium milk to soft dough (GS 75-85) was used to distinguish between low and high risk. High risk of the Septoria diseases was predicted when the number of days with precipitation above or equal to $1 \mathrm{~mm}$, calculated during a period of 30 days, was above 8 for susceptible and above 9 for resistant winter wheat varieties. However, a spraying threshold of 7 to 8 days with precipitation above or equal to $1 \mathrm{~mm}$ during the last 30 days was recommended, because the resulting yield gain from two fungicide sprays justified the fungicide costs under these conditions. This 'Hansen model' has been adjusted and implemented in the Danish decision support system Crop Protection Online (CPO) to optimize fungicide inputs in winter wheat (Hagelskjær and Jørgensen 2003).

Based on the 'Hansen model' developed for winter wheat, a Norwegian LBD prediction model was developed to estimate the level of LBD severity and assess the need for fungicide treatment in spring wheat using Norwegian field observations (Elen 2007). The starting value for disease development in this model is corrected for by host resistance, tillage and crop rotation. The main factors driving the model are the number of days with precipitation above $1 \mathrm{~mm}$ and the total amount of precipitation over a certain time. The model estimates the level of LBD severity and the need for fungicide treatment over time. To increase the accuracy of the recommended spraying time, the model was adjusted on a yearly basis according to spring wheat trial observations in Norway. This model was included in the Norwegian decision support system VIPS (www.vipslandbruk.no) in 2001 and is currently available to farmers and agricultural extension services. VIPS is a Norwegian open source information platform that implements IPM tools, by making pest and disease forecast risk models for agricultural and horticultural crops available. Testing of this 'VIPS 2001' model for
LBD in wheat with Norwegian field data from 2010 to 2017 showed that it had the tendency to overestimate the need for fungicide applications (Ficke et al. 2019).

It is known that host susceptibility and disease development of stripe rust changes with the developmental stage of the wheat plant (Farber and Mundt 2017). Resistance mechanisms in durum wheat to DTR were shown to differ between plant organs and to be under different genetic control depending on the host phenological growth stage (Fernandez et al. 1994). Jones and Odebunmi (1971) showed that later inoculations of spring wheat variety 'Opal' with $P$. nodorum lead to larger reduction in grain size and numbers than earlier inoculations. The greater SNB development at later growth stages was also confirmed by Wainshilbaum and Lipps (1991). No such effect was observed for $Z$. tritici in the same study (Wainshilbaum and Lipps 1991). The dynamic hostpathogen interactions over different phenological stages lead us to hypothesize that different weather variables can have a different effect on LBD development at different growth stages in the spring wheat development as well.

The objective of this study was to develop a new prediction model for LBD risk in spring wheat during the milk development stage (GS 70-79), based on host resistance, previous crop and weather factors during different phenological growth stages. The study was performed in three different steps: (1) a model was developed to predict spring wheat phenological development, (2) the associations between LBD severity and weather conditions during different phenological growth stages was determined in a correlation study, and (3) three models to predict the risk of LBD (classified at a 5\% severity threshold, as used by Hansen et al. 1994) were developed and further compared with two existing models ('VIPS 2001' and the 'Hansen-model'). Our goal was to develop a disease prediction tool with high accuracy and sensitivity that could be included in the integrated management of LBD in spring wheat.

\section{Material and methods}

Part 1: Phenological model to predict spring wheat development

\section{Phenological growth stage data from field trials}

Data on phenological growth stages of spring wheat were obtained from field trials conducted by NIBIO 
and the Norwegian extension service. A total of 153 observations of average phenological growth stage were recorded in different field trials between 2009 and 2016, with most data collected in 2015 (24\%) and 2016 (19\%). All observations were from South Eastern Norway, representing the main production area $(>95 \%)$ for wheat in Norway. The phenological growth stages (GS) of the spring wheat plants were observed between GS 12 (seedling growth, two leavers unfolded) and GS 90 (ripening). For all observations, field location and sowing date was recorded in addition to the phenological growth stage of the plants at a specific date.

\section{Weather records connected to the growth stage observations}

Mean daily records of air temperature $\left(\mathrm{T} ;{ }^{\circ} \mathrm{C}\right)$, minimum daily air temperature $\left(\mathrm{T}_{\min } ;{ }^{\circ} \mathrm{C}\right)$ and maximum daily air temperature $\left(\mathrm{T}_{\max } ;{ }^{\circ} \mathrm{C}\right)$ were provided by the nearest weather station owned by Agrometeorology Norway (2020) and downloaded via the national agricultural meteorological services (https://lmt.nibio.no/). Additionally, the environmental variable photoperiod $\left(\mathrm{Ph}, \mathrm{h}\right.$ day $\left.^{-1}\right)$, which is the number of daylight hours, was calculated based on the latitude of the nearest weather station and the day of the year according to Olseth and Skartveit (1985). All weather stations were within a distance between 0 and $22 \mathrm{~km}$ from the field trials we recorded the phenological growth stages from.

\section{Development of a model to predict phenological growth} stages of spring wheat

Mathematical models were constructed to predict phenological growth stages of spring wheat (see $e$-Xtra Table $S 1$ ). Nineteen different models were proposed based on the Gompertz function (Batschelet 1976). The models depended on air temperature alone or in combination with photoperiod, which are the two main environmental variables affecting crop growth (Shaykewich 1995).

According to the cross-year validation technique (Landschoot et al. 2012), the data were grouped by year, and for each subset with observations from a specific year, the model was fitted to the remaining dataset (without using the observations of the subset under consideration). Thereafter, the observations in the subset were used to evaluate the predictive performance of the model. The Bayesian calibration framework (Robert and Casella 1999) was used to best fit the model to observed data, while the root mean square error of validation (RMSEV) was included for model evaluation and to select the best model to predict spring wheat development.

Part 2: Associations between leaf blotch disease severity and weather conditions during different phenological growth stages in spring wheat

\section{Field data of leaf blotch disease severity}

Observations of LBD severity were obtained from field trials conducted by NIBIO and the Norwegian extension service (not the same dataset as described in Part 1). This dataset was collected in the same area and during the same time period than the one for determining phenological growth stages. Not all trials that contained data on phenological stages contained the data on LBD severity, so the two datasets contain a different selection of field trials. The LBD severity was recorded as the average percentage of the leaf area with LBD symptoms on the upper two to three leaves per plant of a total of 25 plants per plot. LBD severity was then averaged over two or three replicates (one plot per replicate) per experimental field. For each observation, registration date, sowing date, previous crop (wheat or not wheat), host resistance level and field location were recorded in addition to LBD severity. Most of the observations (99\%) were from field trials located in South Eastern Norway (Viken $-63 \%$, Innlandet $-19 \%$ and Vestfold and Telemark - 17\%) and the remaining $1 \%$ from Middle Norway (Trøndelag). Only observations conducted during milk development stage (GS 70-79) were included in the dataset. Moreover, observations with missing values or poor quality of weather data (especially relative humidity records) were discarded. The remaining data set contained 283 observations of LBD severity and were collected between 2002 and 2018 (no suitable data was available for 2004 and 2006). More than $97 \%$ of the fields were ploughed, making the data unsuitable for testing the effect of tillage on LBD severity. Almost $20 \%$ of the fields had wheat as previous crop, and the resistance factor of the host to LBD varied between three and seven (Russenes et al. 2019), where one is most susceptible and 10 least susceptible.

The observed severity of LBD varied between $0 \%$ and $100 \%$ infection and the mean severity across all field trials was $15 \%$ with a median value of $6 \%$. A total 
of 177 observations (63\%) were recorded with LBD severity above or equal to $5 \%, 120$ observations (42\%) with LBD severity above or equal to $10 \%$, and 71 observations (25\%) with LBD above or equal to $20 \%$. The 283 observations of LBD severity were divided randomly into a training dataset of 189 observations $(67 \%)$ and a test dataset of 94 observations (33\%).

\section{Weather records connected to the leaf blotch disease severity observations}

Hourly air temperature $\left(\mathrm{T} ;{ }^{\circ} \mathrm{C}\right)$, precipitation $(\mathrm{P} ; \mathrm{mm})$ and relative humidity (RH; \%) were obtained from 14 different weather stations of the Agrometeorology Norway (https://lmt.nibio.no/). Additionally, vapor pressure deficit (vpd; $\mathrm{kPa}$ ) was estimated. Saturated vapor pressure was estimated from measured air temperatures according to Goff and Gratch (1946), while the actual vapor pressure deficit was derived from the estimated saturated vapor pressure and the measured relative humidity (Perry and Green 1997).

\section{Data analysis}

The associations between LBD severity in spring wheat during milk development stages and weather conditions during different phenological growth stages were assessed in a correlation study based on the methodology introduced by Coakley et al. (1982), later called 'window-pane'. For each observation of LBD severity, growth stages were estimated daily between sowing and end of flowering by the phenological model developed in this study (SWM1, presented in the results below). Flowering (GS 65) is usually the last stage at which fungicides can be applied in Norway, as there must be a 5week period between the last application of fungicides and the time of harvest. These estimated phenological growth stages were further separated into six groups (phenological windows), reflecting the different plant developmental stages that correspond to germination/ seedling growth, tillering, stem elongation, booting, heading, and flowering (Table 1). Additionally, a seventh group was constructed by combining the tillering and stem elongation windows, as the number of observations of growth stage data from these two periods were limited in the dataset used to develop SWM1. Based on our understanding of LBD epidemiology, 139 different weather summarisations (air temperature, precipitation, relative humidity and vapor pressure deficit) were defined (see $e$-Xtra Table S2) and calculated within each phenological window for the training data of LBD severity. Possible associations between LBD severity during the milk development stage and the estimated weather summarisations were calculated using the Pearson (assesses the linear relationship between two continuous variables) and the Spearman correlation coefficients (assesses the ranked values for each variable). The training data were randomly split into two different datasets, and the correlation study repeated for both datasets separately to ensure robustness. Weather summarisations with a significant (5\% level) correlation (Pearson or Spearman) to LBD severity, for both datasets, were retained as important weather conditions for LBD development and included as possible factors in the LBD risk model. Several of these summarisations were highly intercorrelated, and for the weather summarisations that were highly correlated $(>0.9)$, only the summarisations with highest correlation to LBD were retained for developing the LBD risk model.

Part 3: Prediction model to classify risk of leaf blotch disease severity

\section{Development of a prediction model to classify risk of leaf blotch disease severity}

In order to develop a classification model to predict the risk of moderate to high LBD severity ( $\geq 5 \%$ ), weather summarizations, host resistance and previous crop were included as variables. Two different algorithms were tested: (1) Classification and Regression Trees (CART), and (2) K-Nearest Neighbors (KNN). The algorithms are respectively (1) a tree-like structure with its root node at the top, and with a set of if-else statements used to classify (Breiman et al. 1984), and (2) a nonparametric memory-based algorithm that requires training data at run time (Altman 2012).

Both algorithms were fitted to the training dataset according to the 5-fold cross validation technique, where the data were divided between five groups, and for each subset with observations from a specific group, the model was fitted to the remaining dataset (without using the observations of the subset under consideration). Thereafter, the observations in the subset were used to evaluate the predictive performance of the 
Table 1 Growth stages with estimated degree days adjusted with photoperiod from sowing to end of flowering stage and mean number of days with standard deviation for each growth stage for Norwegian spring wheat based on observations in field trials in the years 2009 to 2016

\begin{tabular}{lllr}
\hline Growth stage (GS) & $\begin{array}{l}\text { Phenological growth } \\
\text { stage windows }\end{array}$ & $\begin{array}{l}\text { Degree days adjusted } \\
\text { with photoperiod from s } \\
\text { owing to end of GS window }\end{array}$ & $\begin{array}{l}\text { Number of days in the } \\
\text { GS window, as mean and } \\
\text { standard deviation }\end{array}$ \\
\hline$\left[\begin{array}{ll}0 & 20)^{*}\end{array}\right.$ & Germination/seedling growth & 255 & $33.5(6.1)$ \\
{$\left[\begin{array}{ll}20 & 30)\end{array}\right.$} & Tillering & 354 & $9.5(1.3)$ \\
{$\left[\begin{array}{ll}30 & 40)\end{array}\right.$} & Stem elongation & 448 & $8.8(0.9)$ \\
{$\left[\begin{array}{ll}40 & 50)\end{array}\right.$} & Booting & Heading & $60)$
\end{tabular}

* The bracket [indicates that the following number is included in the interval while) indicates that the previous number is not included

model. Contingency tables were developed and summary statistics of accuracy, sensitivity (percentage of predictions correctly classified as moderate to high presence of LBD $(\geq 5 \%)$ ) and specificity (percentage of predictions correctly classified as low presence of LBD $(<5 \%)$ ) calculated. Further, model selection was based on the accuracy, but also simplicity, biological relevance, sensitivity and the values of the false positives (falsely classified as low presence of LBD).

\section{Model testing and comparison}

The best models to predict risk of LBD in spring wheat, developed in this study were tested on the separate test dataset that was not included in model development. Additionally, the 'VIPS 2001' model and the 'Hansen model' were tested with the same test data. The Hansen model was developed to predict development of Septoria spp. in winter wheat under Danish weather conditions and requires the host growth stage as input. Before testing this model, the growth stages of the spring wheat fields included in our dataset were calculated by using the phenological model developed in our study (SWM1, presented in the results below). Contingency tables were created, and model accuracy, sensitivity and specificity calculated and used to assess if the new models would outperform the two older LBD forecasting models.

\section{Software}

MATLAB R2019a was used for the data mining and for the model development.

\section{Results}

Phenological model to predict spring wheat development

Nineteen different mathematical models to estimate phenological growth stages of Norwegian spring wheat were developed based on air temperature alone or in combination with photoperiod (see $e$-Xtra Table $\mathrm{S} 1$ ). The predictive performance was estimated for each proposed model, and the one with lowest error term (root mean square error of validation, RMSEV) was selected as the best model to predict spring wheat development under Norwegian conditions (hereby referred to as SWM1). The model is described in Eq. 1.

$G S_{i}=\min \left(96.4 \cdot e^{-3.388 \cdot e^{-0.003 \cdot D D_{i}}}, 90\right)$

The model predicts daily growth stages $\left(G S_{i}\right)$ and is driven by the adjusted degree day $\left(D D_{i}\right)$ which is described in Model 6 in the $e$-Xtra (Table S1). Specifically, the adjusted degree day is here defined as the accumulated air temperature from sowing to day $i$, using a lower boundary base air temperature of $0{ }^{\circ} \mathrm{C}$ and with an additional weighing function by photoperiod (the relative number of day light hours). The output from the SWM1 model is plotted together with field observations in Fig. 1. Table 1 shows the adjusted degree days and the number of days for the previously defined phenological growth stage windows until flowering (GS 65), estimated for Norwegian spring wheat based on the SWM1 model. From the model, end of flowering (GS 65) was estimated at 715 adjusted degree days from sowing (Table 1), while mature grain (GS 90) was 
Fig. 1 Estimated phenological development of Norwegian spring wheat from the SWM1 model (curve) together with observed data (dots)

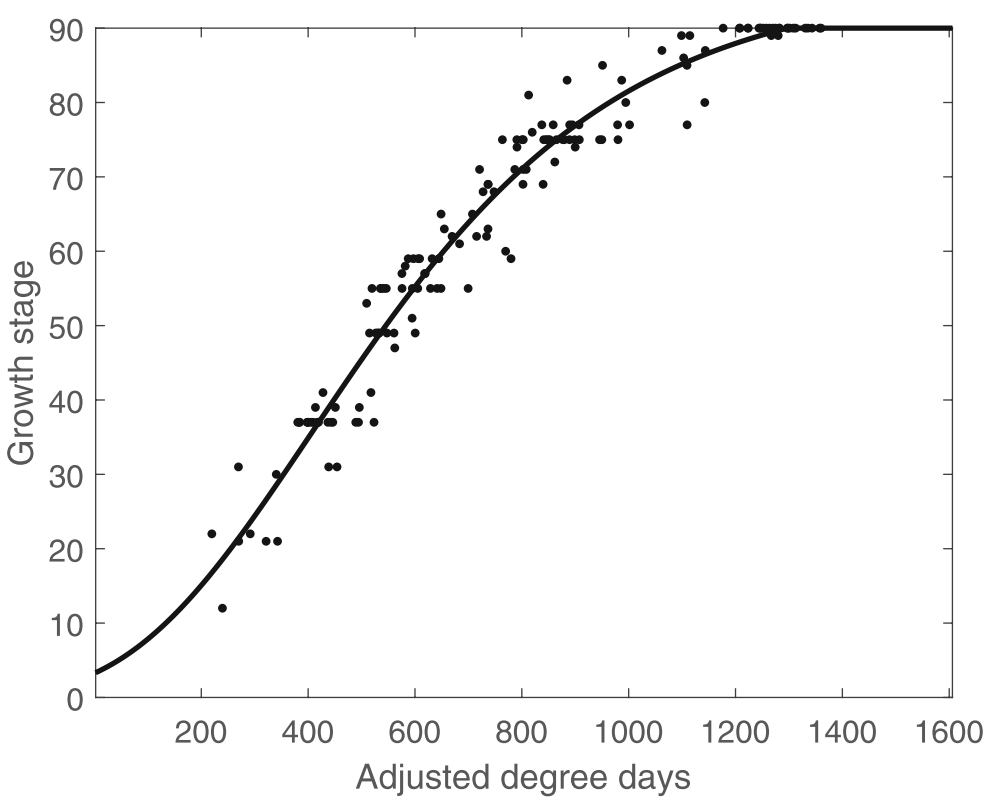

estimated at 1298 adjusted degree days from sowing. From the observed data, the average time between sowing and end of flowering was 74 days (Table 1), and 138 days from sowing to estimated ripening (GS 90). The number of days between sowing and GS 87 (hard dough) of spring wheat is in this paper referred to as the growth period, and the duration of this period was estimated to be 117 days using this dataset, with a variation between 102 and 138 days depending on location and sowing day.

Associations between leaf blotch disease severity in spring wheat and weather conditions at different phenological growth stage windows

The SWM1 model was used to predict the starting date of each of the seven defined phenological growth stage windows (germination and seedling growth, tillering, stem elongation, booting, heading, flowering and the combined tillering and stem elongation window) for all the observations of LBD severity in the training dataset. The 139 weather summarisations defined ( $e$-Xtra Table S2) were estimated within each of the seven phenological windows and then correlated with LBD severity during the milk development stage. This was done separately for two splits of the LBD datasets. The weather summarisations with significant $(p<0.05)$ correlation (Pearson or Spearman) to LBD severity for both splits of the data, were retained as important weather conditions for LBD development and listed in the $e$-Xtra (Table S3 and Table S4). To reflect some major findings in the association between LBD severity in spring wheat and weather conditions during different phenological windows, three important weather summarisations are visualized in Fig. 2.

Figure 2a shows the Pearson correlation between LBD severity and rainy periods (occurrence of $\geq 8$ consecutive hours with precipitation $>0.2 \mathrm{~mm}$ ) for each of the six defined growth stage windows. LBD severity was positively and significantly $(p<0.05)$ correlated with rainy conditions during stem elongation. During the other phenological windows, this weather summarisation was not significantly associated with LBD severity.

Figure $2 \mathrm{~b}$ shows the Pearson correlation between LBD severity and moist conditions (relative humidity $>80 \%$ ) for each of the six defined growth stage windows. A positive significant $(p<0.05)$ correlation was identified between LBD severity and moist conditions from stem elongation to heading, with highest association during booting.

Figure $2 \mathrm{c}$ shows the Pearson correlation between LBD severity and air temperatures between 15 and $30{ }^{\circ} \mathrm{C}$ combined with and no rain $(P \leq 0.2 \mathrm{~mm})$ for each of the six defined growth stage windows. This shows a negative significant $(p<0.05)$ correlation between LBD severity and the daily number of hours with the combination of high air temperatures $\left(15-30{ }^{\circ} \mathrm{C}\right)$ combined with no rain during tillering. 
Development of a prediction model to classify risk of leaf blotch disease severity

Two binary CART models to classify moderate to high risk ( $\geq 5 \%$ ) of LBD severity during milk development stage were selected based on accuracy and sensitivity to predict LBD severity, referred to as CART1 and CART2. Both models turned out to be purely weather based.

The CART1 model (Fig. 3) predicted risk of moderate to high LBD severity when the average daily number of hours with air temperature between 15 and $30{ }^{\circ} \mathrm{C}$ combined with precipitation $\leq 0.2 \mathrm{~mm}$ during tillering was below $16.3 \mathrm{~h}$ and the daily temperature fluctuation (difference between the daily maximum and minimum air temperature) during booting was below $9.1^{\circ} \mathrm{C}$. Additionally, the model predicted risk of moderate to high LBD severity when the average daily number of hours with air temperature between 15 and $30{ }^{\circ} \mathrm{C}$ combined with precipitation $\leq 0.2 \mathrm{~mm}$ during tillering was below $16.3 \mathrm{~h}$, the daily temperature fluctuation (difference between the daily maximum and minimum air temperature) during booting was above $9.1^{\circ} \mathrm{C}$, and the average daily number of hours with air temperature between 15 and $20{ }^{\circ} \mathrm{C}$ combined with relative humidity $>70 \%$ during booting was above 1.7. Based on cross validation, CART1 had an accuracy of $80 \%$ with a sensitivity of 94\% (predictions correctly classified with moderate to high severity of LBD) and a specificity of $52 \%$ (predictions correctly classified with low severity of LBD). This gave a low percentage of false negative $(6 \%)$ and a high percentage of false positive (48\%).

The CART2 model (Fig. 4) predicted risk of moderate to high LBD severity when the average daily number of hours with air temperature between 15 and $30^{\circ} \mathrm{C}$ and precipitation $\leq 0.2 \mathrm{~mm}$ during tillering was below $16.3 \mathrm{~h}$ and the daily number of hours with relative humidity $>80 \%$ during booting was more than $3.7 \mathrm{~h}$. From the cross validation, an accuracy of $80 \%$ was calculated with a sensitivity of $98 \%$ (predictions correctly classified with moderate to high severity of LBD) and a specificity of $46 \%$ (predictions correctly classified with

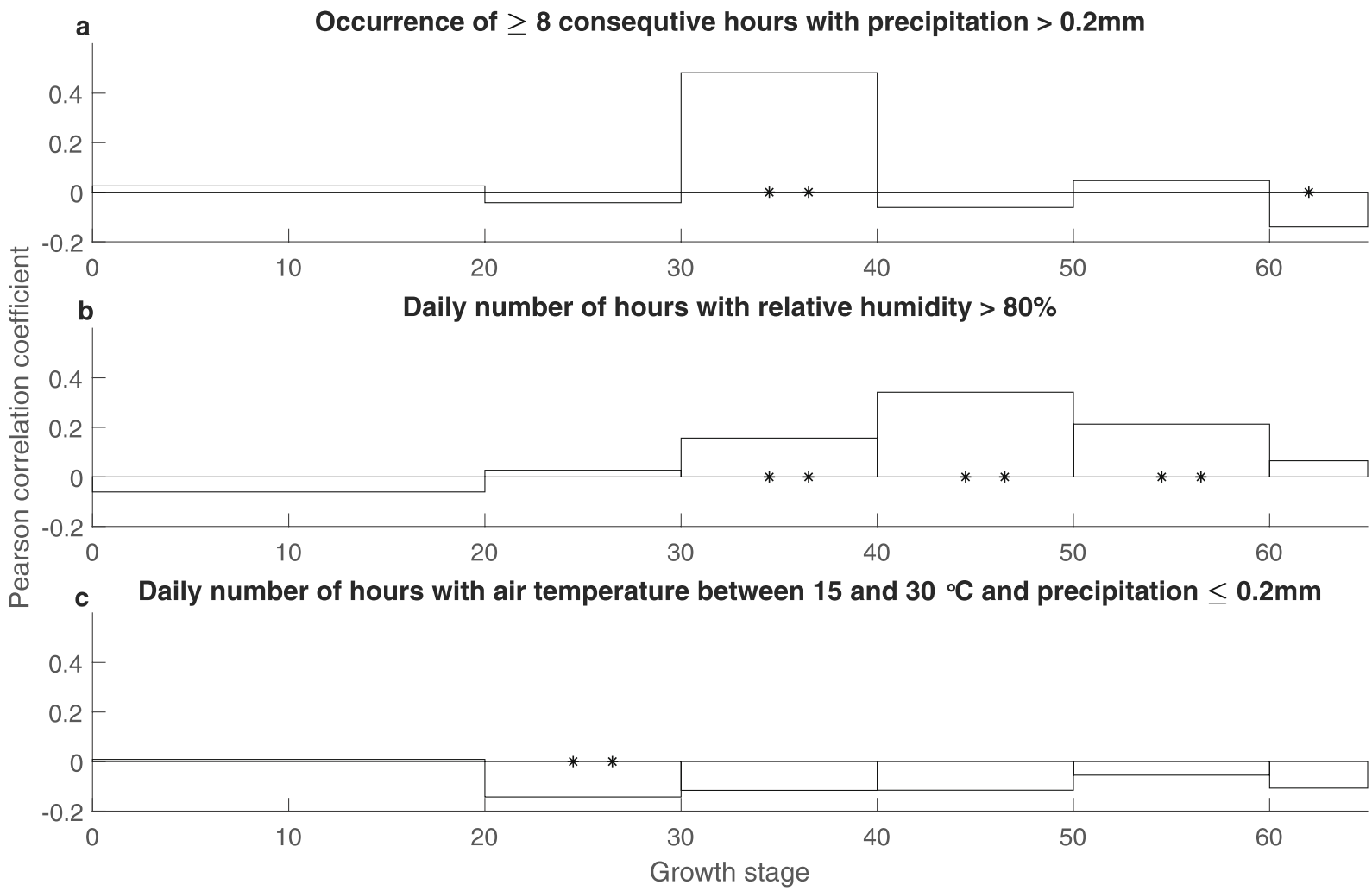

Fig. 2 The Pearson correlation coefficient calculated between LBD severity (\% infection) at the milk development stage in Norwegian spring wheat and different weather factors, during estimated growth stage windows (GS). Asteriks indicate that the correlation is significant at the $10 \%$ level (*) or at the $5 \%$ level (**) 


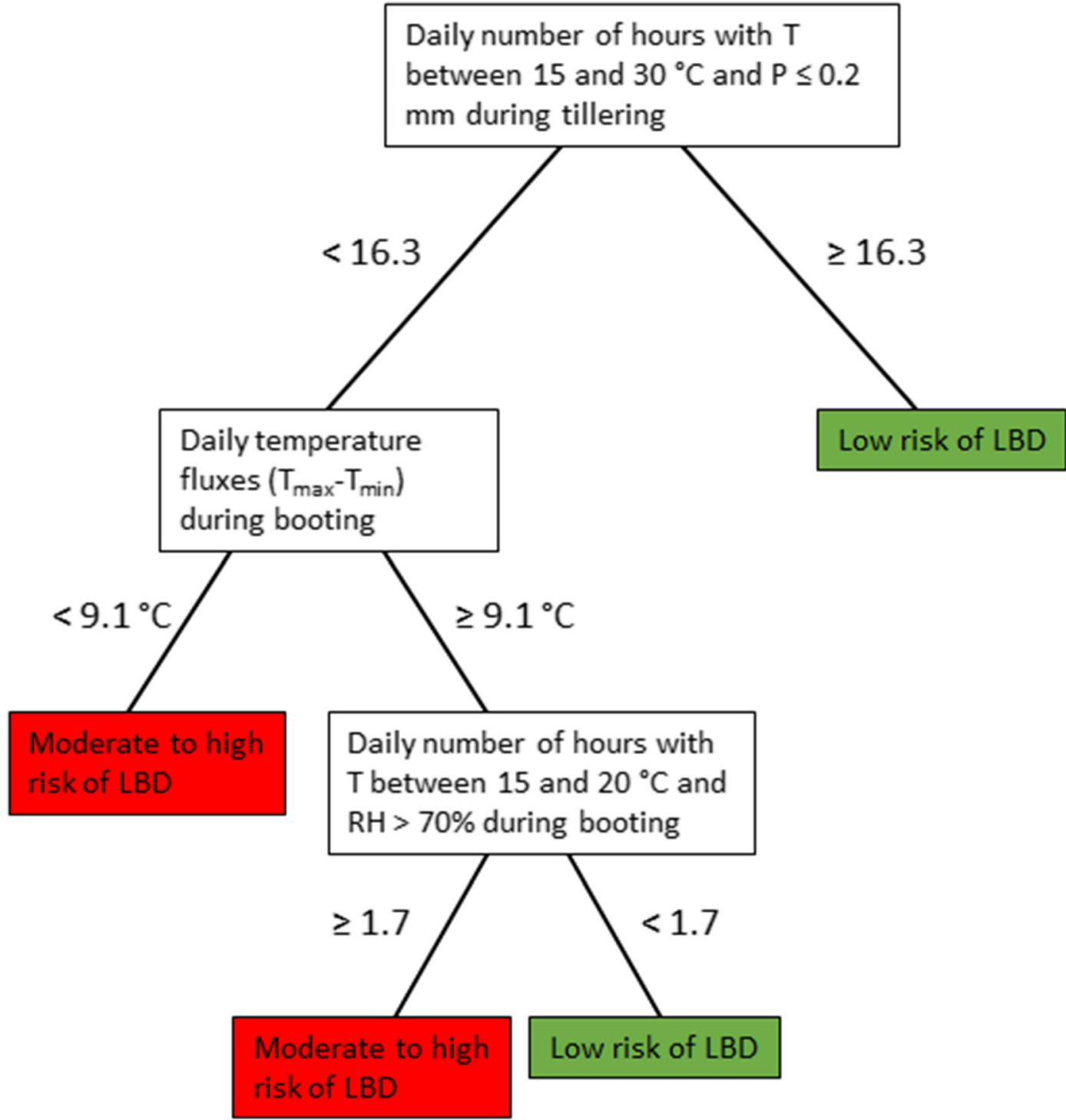

Fig. 3 The CART1 model, a binary classification and regression tree to predict the risk for moderate to high LBD severity $(\geq 5 \%$ infection) based on weather conditions (mean air temperature $\mathrm{T}$,

low severity of LBD). This led to a low percentage of false negatives $(2 \%)$ and a high percentage of false positive (54\%).

One KNN model was selected based on accurate classification of LBD severity (KNN1). Using the validation data, the model had an accuracy of $85 \%$, with a sensitivity of $90 \%$ (predictions correctly classified with moderate to high severity of LBD) and a specificity of $73 \%$ (predictions correctly classified with low severity of LBD). This lead to a low percentage of false negative $(10 \%)$ and a moderate percentage of false positive (27\%).

minimum air temperature Tmin, maximum air temperature Tmax, precipitation $\mathrm{P}$ and relative humidity $\mathrm{RH}$ ) during different phenological windows in Norwegian spring wheat

Model comparison and predictive accuracy

The predictive performance of the three models developed and selected in this study were calculated with the test data set consisting of 94 observations of LBD severity (Table 2). The two CART models performed in the same range as with cross validation based on the training test data set, with a predictive accuracy of $78 \%$ and $76 \%$ respectively for CART1 and CART2. Both models had a high sensitivity of $100 \%$ and $98 \%$ respectively, with correspondingly few false negatives 


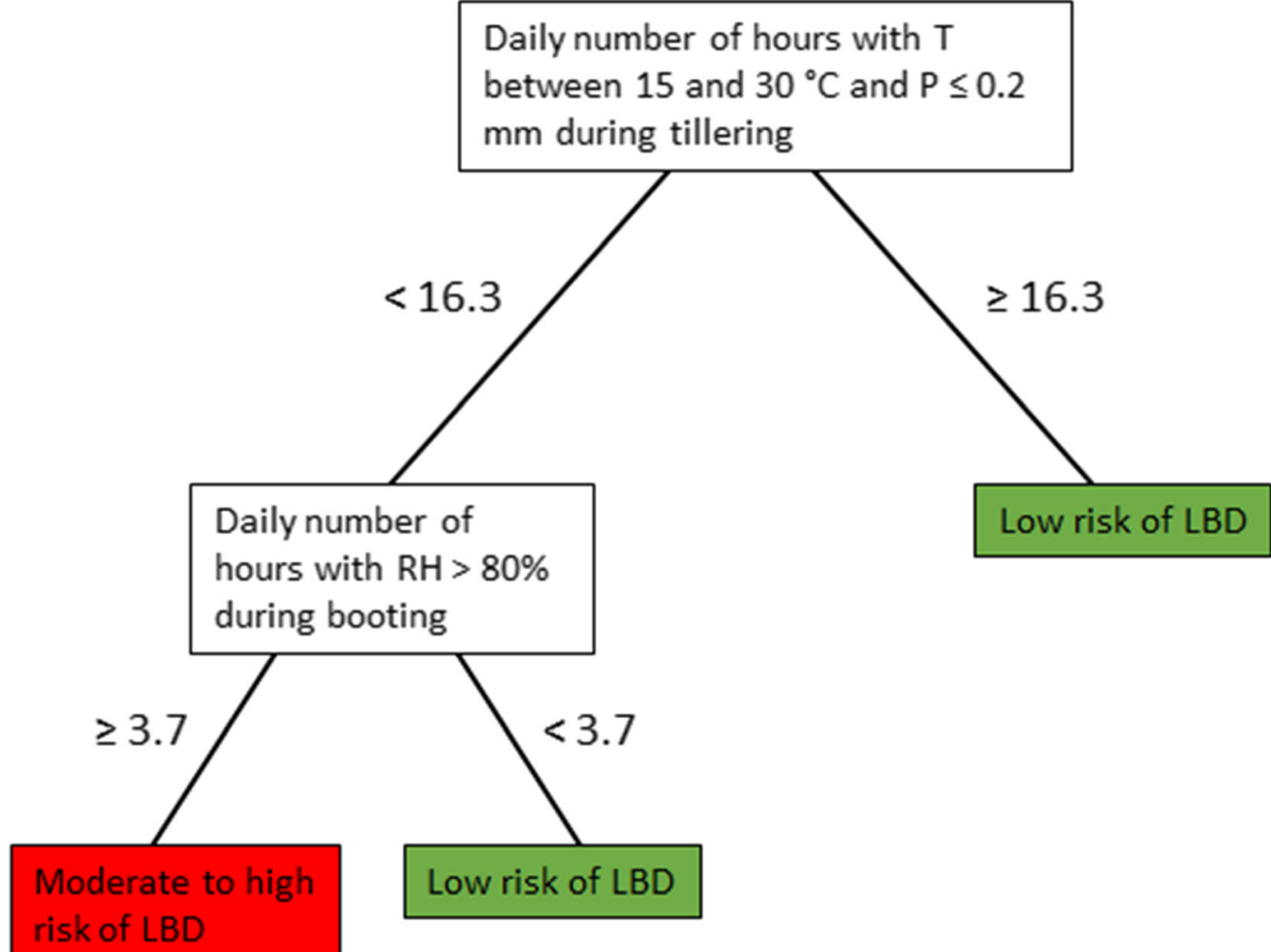

Fig. 4 The CART2 model, a binary classification and regression tree to predict the risk for moderate to high LBD severity $(>5 \%$ infection) based on weather conditions (mean air temperature $\mathrm{T}$,

(Table 2). Only one observation of $15 \%$ LBD severity was misclassified with low risk. Despite the high sensitivity, the CART models performed with specificities of $51 \%$ (CART1) and 49\% (CART2). The KNN1 model performed with a higher accuracy $(83 \%)$ than both CART models. The sensitivity was slightly lower (90\%), but the highest observed value of the $10 \%$ false

Table 2 The performance (accuracy, sensitivity and specificity) of the three models developed in this study (CART1, CART2 and KNN1), an on-line forecasting model ('VIPS 2001') and the precipitation $\mathrm{P}$ and relative humidity $\mathrm{RH}$ ) during different phenological windows in Norwegian spring wheat

negatives was only $12 \%$ LBD severity. In addition, the KNN1 model had a much higher specificity (74\%) than CART1 models as it misclassified fewer observations with moderate to high LBD severity.

Both the 'VIPS 2001' and the 'Hansen model' were tested on the same test set as the newly developed models in this study. Based on the test data set, we

'Hansen model' to predict the risk of LBD severity (> 5\% infection) in Norwegian spring wheat based on the test data set

\begin{tabular}{llll}
\hline Model & Accuracy $(\%)$ & Sensitivity ${ }^{1}(\%)$ & Specificity $^{2}(\%)$ \\
\hline CART1 & 78 & 100 & 51 \\
CART2 & 76 & 98 & 49 \\
KNN1 & 83 & 90 & 74 \\
'VIPS 2001' & 60 & 76 & 40 \\
'Hansen model' & 61 & 80 & 37 \\
\hline
\end{tabular}

${ }_{1}^{1}$ percentage of predictions correctly classified as moderate to high presence of LBD ( $\geq 5 \%$ disease severity)

${ }^{2}$ percentage of predictions correctly classified as low presence of $\operatorname{LBD}(<5 \%$ disease severity $)$ 
estimated the predictive accuracy of the models to be $60 \%$ and $61 \%$ for the 'VIPS 2001' model and the 'Hansen model', respectively. Also, for these models, the sensitivity was higher than the specificity, $76 \%$ and $40 \%$ for the 'VIPS 2001' model and $80 \%$ and $37 \%$ for the 'Hansen model'. Among the false negatives, the highest LBD severity misclassified with low risk was respectively $75 \%$ and $42 \%$ for these two models.

\section{Discussion}

The goal of our work was to develop a prediction model for LBD risk in spring wheat under Norwegian conditions that would perform better than the model currently used in the Norwegian decision support platform VIPS. VIPS is an important tool for the Norwegian farmers in the integrated management of diseases and pest in several crops. For development and validation of a LDB risk model, data from field observations of LBD in spring wheat were collected between 2002 and 2018 from the main cereal growing areas of Norway, and weather data were collected from the nearest weather stations. Several models were designed using both the CART and KNN algorithms to identify factors (host resistance, previous crop, and weather summarizations during different phenological windows) associated with development of LBD in Norwegian spring wheat. The performance of the prediction models based on CART was not improved by including information on host resistance and previous crop. Thus, the selected CART models are purely weather based. The KNN approach is on the other hand based on a non-parametric evaluation of similarity. The algorithm stores all the available data and classifies the new data points to the class most common among its nearest neighbors. Hence, all factors (host resistance, previous crop and weather summarizations during different phenological windows) contribute in the classification, but with different weight.

As disease development and the associated need for fungicide application is closely related to weather conditions during plant development, we tested the association between LBD severity and weather conditions at defined plant growth stages. The data set we had available for developing our disease risk model did rarely include information on observed growth stages. Therefore, so as to obtain weather data related to a specific growth stage period, a mathematical model (SWM1) was developed to calculate the starting dates and duration of different growth stage periods for each spring wheat field included in this study. For the various stages of plant development, weather factors highly associated with risk of LBD, could then be identified.

Among the 19 simple models derived in this study to estimate phenological development of spring wheat in Norway, the model named SWM1 was selected as the best model because of the lowest error term. All proposed models followed the Gompertz growth function of degree-days, in line with Shaykewich (1995), who concluded that developmental rate of cereal crops was a sigmoid function of degree-days. As other studies agree, air temperature and photoperiod are the two most important factors for spring wheat development (Davidson and Campbell 1983; Olesen et al. 2012; Yan and Wallace 1998; Saarikko and Carter 1996), and only these environmental variables were evaluated in this study and combined in SWM1. Other factors, such as N fertility, soil moisture or water stress appeared to have no direct effect on spring wheat development in other studies (Davidson and Campbell 1983; Penning de Vries et al. 1989) and were therefore not considered here. The base temperature is the threshold temperature, at which no plant growth takes place. A base temperature of both $0{ }^{\circ} \mathrm{C}$ (Wang and Engel 1998; Dofing and Knight 1992) and $5{ }^{\circ} \mathrm{C}$ (Olesen et al. 2012; Saarikko and Carter 1996) are common to use and a base temperature of $0{ }^{\circ} \mathrm{C}$ turned out to fit the Norwegian spring wheat data best. From the SWM1 model, the growth period from sowing to GS 87 was estimated to be 117 days on average, varying between 102 and 138 in our data set. However, the growth period (the number of days between sowing and GS 87) is observed to vary between 120 and 127 days for the most common spring wheat varieties grown in Norway (Russenes et al. 2019). Hence, on average the phenological model slightly underestimated the number of days between sowing and hard dough (sowing - GS 87) but gave a high variation in estimated number of days. This large variation in the estimated growth period might be due to the extended sowing period for spring wheat in Norway, which can vary strongly between sites and years due to differences in soil temperature along the cereal growing area (it varied between 16th April and 6th June in our data set). Nonetheless, the predicted number of days between sowing and flowering (sowing - GS 65), when disease risk classification is most relevant, was within a reasonable estimate.

Weather conditions during the phenological windows stem elongation and booting were identified as most 
decisive for LBD severity in the correlation analysis. Both CART models showed a negative correlation between moderate to high LBD severity and a dry period $(P<0.2 \mathrm{~mm})$ with temperature between 15 and $30{ }^{\circ} \mathrm{C}$ during tillering. This is not surprising, as the primary inoculum is most likely coming from infected plant material at the soil surface, and/or from infected untreated seeds. Extended dry and warm periods during tillering will stop the splash dispersal of the LBD pathogen $P$. nodorum and prevent infection of the young leaves, delaying the start of the epidemic considerably. Once the stem elongation period starts (GS 30), the splash dispersed spores from the soil or lowest leaf level might not reach the upper leaves to colonize successfully the third, second and first leaf which were assessed for LBD severity in our study. Royle et al. (1986) mentioned that the risk of dispersal for Septoria species is highest during stem elongation of wheat. If there is no efficient vertical dispersal during stem elongation, the risk for infection of the upper leaves and the head is reduced (Royle et al. 1986). Ascospores might still be able to infect the upper leaf layers but could be arriving too late in the season and in too low numbers to cause significant damage in Norway (Ficke et al. 2016b). Number of hours with high humidity (RH $>70-80 \%$ ), daily temperatures between 15 and $20{ }^{\circ} \mathrm{C}$ and/or large temperature fluctuations $\left(\mathrm{T}_{\max }-\mathrm{T}_{\min }\right)$ during booting were positively correlated with the risk of high LBD severity. Humidity is a major prerequisite for sporulation and spread of LBD across the leaf surface. At the booting stage, the upper two leaves including the flag leaf might already be infected by splash dispersed conidia and the high humidity will then lead to optimal sporulation conditions and high LBD severity on these leaf layers. It is peculiar that high temperature fluctuations were correlated with severe LBD infections. However, during cool, clear nights and warm days, when temperature fluctuations are rather large, Norway can experience extended dew periods, which could explain the positive correlation between increased infection risk and those temperature conditions.

Both CART models can be interpreted by using knowledge of the biology of pathogens causing LBD and the host plant, as they show the important effect of weather during different phenological windows on the LBD severity. Beside the weather factors, host resistance level and previous crop were included in the model development and then discarded, as only weather factors appeared significantly correlated with LBD severity based on our data set. However, the agronomic factors, such as previous crop, tillage and host resistance are highly relevant for LBD disease development in general and should be considered when interpreting the results from the weather-based LBD risk classification.

In contrast to the CART models, the KNN model classifies based on similarity to other data. Specifically, each data to be classified by KNN1 was assigned to the class most common among its ten nearest neighbors, in the space spanned by all factors (weather factors, host resistance level and previous crop). As it is a nonparametric memory-based algorithm, no further biological interpretation of the model is possible.

The three new models were compared to two 'older' regression models, 'VIPS 2001' (Elen 2007) used by the Norwegian extension service, and with the 'Hansen model' (Hansen et al. 1994) based on their accuracy, sensitivity and specificity. The 'VIPS 2001' model and the 'Hansen model' consider precipitation as the most important parameter for LBD risk prediction and do not include humidity. Also, the 'Hansen model' was developed for winter wheat, but adapted for spring wheat, based on the SWM1 phenological model in our comparison. Both models showed an overall accuracy of about $60 \%$ and specificity of about $40 \%$, indicating that they both overestimated LBD risk for the Norwegian data. All three new models developed here performed better than the 'older' models for these characteristics. The KNN model had the overall highest accuracy ( $83 \%$ ) and specificity (74\%). Sensitivity on the other hand was highest for the two CART models, but these models also had a tendency to overestimate LBD infection, and predicted risk of moderate to high LBD severity when the risk was actually low in ca $50 \%$ of the tested cases (model specificity). However, based on feedback obtained from extension specialists, overestimation of risk is preferable to underestimation of the risk (model sensitivity). A user will quickly lose trust and interest in using decision support tools if the use of these tools leads to 'missing' fungicide applications that were actually needed. In addition, a prediction of 'high risk' will not necessarily lead to a fungicide spray, as it only indicates to the user that the weather conditions were favorable for infection. The final decision on the actual need for action, will depend also on other agronomic factors, such as previous crop, tillage, crop density, grain prices, yield expectations and host resistance level.

Every model is only a simplification of the actual situation in the field and is based on several assumptions that might not be fully met in the field. Our models 
include an estimation of growth stages of wheat based on a given sowing date and temperature for the actual field. Furthermore, the humidity and precipitation data came from weather stations in the area, not from in-field weather stations, which could lead to incorrect weather input for LBD risk prediction. In Denmark, farmers have stopped using local weather stations for predicting disease risk and are now using interpolated weather data from the Danish Meteorological Institute (Bligaard et al. 2016). These additional uncertainties regarding growth stage estimates and weather data input constitute important sources of error that can contribute to the relatively low specificity. An additional source of uncertainty is the composition of the LBD complex which is currently dominated by SNB in Norway. Future changes in the climate and/or agricultural practices can lead to a shift in this complex towards STB and/or DTR, which might lead to poorer performance of the developed model.

With these considerations in mind, we have designed three risk models that capture the most relevant factors for leaf blotch development on spring wheat in Norway. These models can be used as forecasting models to guide farmers decisions under the current Norwegian growing conditions. Even though the new models appear to have a higher accuracy than the two older models, we are aware that their performance might change under future weather conditions and possible alterations in the composition of the LBD complex.

Supplementary Information The online version contains supplementary material available at https://doi.org/10.1007/s10658021-02235-6.

\begin{abstract}
Acknowledgements This research was funded by the Research Council of Norway through the SMARTCROP project (project number 244526). Field experiments conducted for data collection were financed by different projects funded by the Research Council of Norway and the Agriculture and Food Industry Research Funds - FFL/JA with support from several industry partners and NIBIO. We also thank the Norwegian Agricultural Extension Service for carrying out the field trials.
\end{abstract}

Authors' contributions Anne-Grete Roer Hjelkrem and Andrea Ficke designed the study. Andrea Ficke and Unni Abrahamsen compiled the data. Andrea Ficke, Guro Brodal and Anne-Grete Roer Hjelkrem selected the data while Anne-Grete Roer Hjelkrem analyzed the data and derived the models with support from Andrea Ficke, Ingerd Skow Hofgaard and Guro Brodal. The first draft of the manuscript was written by AnneGrete Roer Hjelkrem and Andrea Ficke with considerable input from Guro Brodal. All authors commented on the following versions of the manuscript. All authors read and approved the final manuscript.

Funding Open access funding provided by Norwegian Institute of Bioeconomy Research. All forms of financial support are acknowledged in the acknowledgement.

\section{Declarations}

Ethical approval This study does not contain any studies with human participants or animals performed by any of the authors.

Consent for publication All authors consent to this submission.

Conflict of interest There is no conflict of interest related to this research.

Open Access This article is licensed under a Creative Commons Attribution 4.0 International License, which permits use, sharing, adaptation, distribution and reproduction in any medium or format, as long as you give appropriate credit to the original author(s) and the source, provide a link to the Creative Commons licence, and indicate if changes were made. The images or other third party material in this article are included in the article's Creative Commons licence, unless indicated otherwise in a credit line to the material. If material is not included in the article's Creative Commons licence and your intended use is not permitted by statutory regulation or exceeds the permitted use, you will need to obtain permission directly from the copyright holder. To view a copy of this licence, visit http://creativecommons.org/licenses/by/4.0/.

\section{References}

Altman, N. S. (2012). An introduction to kernel and nearestneighbor nonparametric regression. The American statistican, 46(6), 175-185.

Batschelet, E. (1976). Introduction to mathematics for life scientists. New York: Springer.

Bergstrom, G. C. (2010). Stagonospora nodorum blotch and Stagonospora avenae blotch. In W. W. Bockus, R. L. Bowden, R. M. Hunger, W. L. Morrill, T. D. Murray, \& R. W. Smiley (Eds.), Compendium of Wheat Diseases and Pests (3rd ed., pp. 75-77). St. Paul: APS Press.

Bhathal, J. S., Loughman, R., \& Speijers, J. (2003). Yield reduction in wheat in relation to leaf disease from yellow (tan) spot and Septoria nodorum blotch. European Journal of Plant Pathology, 109(5), 435-443.

Bligaard, J., Jørgensen, L.N., Nielsen, G.C., Ørum, J.E., Hansen, J.G., Axelsen, J., Baby, S., Pedersen, L.H. (2016). Septoriamodel med vejrdata versus en Septoria Timer i afgrøden. Summary of presentation at Plantekongress 2016, Danmark, 136-137. 
Breiman, L., Friedman, J., Olshen, R., \& Stone, C. (1984). Classification and regression trees. Boca Raton: CRC Press.

Chungu, C., Gilbert, J., \& Townley-Smith, F. (2001). Septoria tritici blotch development as affected by temperature, duration of leaf wetness, inoculum concentration, and host. Plant Disease, 85(4), 430-435.

Coakley, S. M., Boyd, W. S., \& Line, R. F. (1982). Statistical models for predicting strip rust on winter wheat in the Pacific northwest. Phytopathology, 72(12), 1539-1542.

Coakley, S. M., McDaniel, L. R., \& Shaner, G. (1985). Model for predicting severity of Septoria tritici blotch on winter wheat. Phytopathology, 75(11), 1245-1251.

Da Luz, W. C., \& Bergstrom, G. C. (1986). Effect of temperature on tan spot development in spring wheat cultivars differing in resistance. Canadian Journal of Plant Pathology, 8(4), 451454.

Davidson, H. R., \& Campbell, C. A. (1983). The effect of temperature, moisture and nitrogen on the rate of development of spring wheat as measured by degree days. Canadian Journal of Plant Science, 63, 833-846.

De Wolf, E. D., \& Francl, L. J. (1998). Empirical infection period models for tan spot of wheat. Canadian Journal of Plant Pathology, 20(4), 394-395.

Djurle, A., \& Yuen, J. E. (1991). A simulation model for Septoria nodorum in winter wheat. Agricultural Systems, 37(2), 193218.

Dofing, S. M., \& Knight, C. W. (1992). Heading synchrony and yield components of barley grown in subarctic environments. Crop Science, 32(6), 1377-1380.

Elen, O. (2007). Forecasting models of disease in barley, wheat and oilseed crops in Norway. NJF 23rd Congress 2007, Trends perspectives and agriculture. NJF Report, 3(2), 209-210.

Farber, D. H., \& Mundt, C. C. (2017). Effect of plant age and leaf position on susceptibility to wheat stripe rust. Phytopathology, 107(4), 412-417.

Faulkner, M. J., \& Colhoun, J. (1976). Aerial dispersal of pycnidiospores of Leptosphaeria nodorum. Journal of Phytopathology, 86(4), 357-360.

Fernandez, M. R., Clarke, J. M., DePauw, R. M., Lopez, G., \& Leeson, S. (1994). Response of durum wheat kernels and leaves at different growth stages to Pyrenophora triticirepentis. Plant Disease, 78(6), 597-600.

Ficke, A., Brodal, G., \& Abrahamsen, U. (2016a). Bladflekksjukdommer og avlingstap i hvete - en komplisert sammenheng (in Norwegian) [leaf blotch diseases and yield losses in wheat - A complicated relationship]. NIBIO BOK, 2(1), 14-147.

Ficke, A., Asalf, B., \& Ruud, A. (2016b). Ascospore biology of Parastagonospora nodorum under Norwegian field conditions. Phytopathology, 106(12), 30-31.

Ficke, A., Dieseth, J. A., Kim, M. O., \& Lillemo, M. (2018a). Bladsjukdommer i norsk hvete. Forekomst, betydning og tiltak. NIBIO BOK, 4(1), 108-115.

Ficke, A., Cowger, C., Bergstrom, G., \& Brodal, G. (2018b). Understanding yield loss and pathogen biology to improve disease management: Septoria nodorum blotch-a case study in wheat. Plant Disease, 102(4), 696-707.

Ficke, A., Olsen, A. K. B., Hjelkrem, A. G. R., Nordskog, B., \& Brodal, G. (2019). Sprøyte eller ikke sprøyte?
Varslingsmodeller for soppsjukdommer i korn og oljevekster. NIBIO BOK, 5(1), 78-82.

Francl, L. J. (1998). Genesis and liberation of conidia of Pyrenophora tritici-repentis. Canadian Journal of Plant Pathology, 20(4), 387-393.

Goff, J. A., \& Gratch, S. (1946). Low-pressure properties of water from -160 to 212 F. In Transactions of the American society of heating and ventilating engineers. New York: American Society of Heating and Ventilating Engineers.

Hagelskjær, L., \& Jørgensen, L. N. (2003). A web-based decision support system for integrated management of cereal pests. EPPO Bulletin, 33, 467-471.

Hansen, J. G., Secher, B. J. M., Jørgensen, L. N., \& Welling, B. (1994). Thresholds for control of Septoria spp. in winter wheat based on precipitation and growth stage. Plant Pathology, 43, 183-189.

Hess, D. E., \& Shaner, G. (1987). Effect of moisture on Septoria tritici blotch development on wheat in the field. Phytopathology, 77(2), 220-226.

Jeger, M. J., Griffiths, E., \& Jones, D. G. (1981). Influence of environmental conditions on spore dispersal and infection by Septoria nodorum. Annals of Applied Biology, 99(1), 29-34.

Jones, D. G., \& Odebunmi, K. (1971). The epidemiology of Septoria tritici and $S$. nodorum: IV. The effect of inoculation at different growth stages and on different plant parts. Transactions of the British Mycological Society, 56(2), 281-288.

Jørgensen, L. N., \& Olsen, L. V. (2007). Control of tan spot (Drechslera tritici-repentis) using cultivar resistance, tillage methods and fungicides. Crop Protection, 26(11), 16061616.

Jørgensen, L. N., Nielsen, G. C., Ørum, J. E., Jensen, J. E., \& Pinnschmidt, H. O. (2008). Integrating disease control in winter wheat-optimizing fungicide input. Outlooks on Pest management, 19(5), 206-213.

King, J. E., Jenkins, J. E. E., \& Morgan, W. A. (1983). The estimation of yield losses in wheat from severity of infection by Septoria species. Plant Pathology, 32(3), 239-249.

Landschoot, S., Waegeman, W., Audeaert, K., Vandepitte, J., Haeaert, G., \& De Baets, B. (2012). Toward a reliable evaluation of forecasting Systems for Plant Disease: A case study using fusarium head blight of wheat. Plant Disease, 96(6), 889-896.

Lupton, F. G. H. (1972). Further experiments on photosynthesis and translocation in wheat. Annals of Applied Biology, 71(1), 69-79.

McMullen, M.P. (2010). Tan spot (yellow leaf spot). In. Bockus, W.W., Bowden, R.L., Hunger, R.M., Morrill, W.L., Murray, T.D., \& Smiley, R.W. (Eds.), Compendium of Wheat Diseases and Pests (3rd ed., pp. 82-84) APS press, St. Paul, MN.

Olesen, J. E., Børgesen, C. D., Elsgaard, L., Palosuo, T., Rötter, R. P., Skjelvåg, A. O., Peltonen-Sainio, P., Börjesson, T., Trnka, M., Siebert, S., Brisson, N., Eitzinger, J., van Asselt, E. D., Oberforster, M., \& van der Fels-Klerx, H. J. (2012). Changes in time of sowing, flowering and maturity of cereals in Europe under climate change. Food Additives \& Contaminants: Part A., 29(10), 1527-1542.

Olseth, J.A., \& Skartveit, A. (1985). Strålingshåndboka. Det norske meteorologiske institutt, 6 . 
Penning de Vries, F.W.T., Jansen, D.M., ten Berge, H.F.M., Bakema, A. (1989). Simulation of ecophysiological processes of growth in several annual crops. Pudoc Wageningen.

Perry, R.H., \& Green, D.W. (1997). Perry's chemical engineers' handbook. McGraw-Hill.

Pietravalle, S., Shaw, M. W., Parker, S. R., \& Van Den Bosch, F. (2003). Modeling of relationships between weather and Septoria tritici epidemics on winter wheat: A critical approach. Phytopathology, 93(10), 1329-1339.

Rapilly, F., \& Jolivet, E. (1976). Construction d'une modele (EPISEPT) permettant la simulation d'une epidemie de Septoria nodorum (Berk.) sur ble. Rev. Statist Appl, 24, 3160.

Robert, C. P., \& Casella, G. (1999). Monte Carli statistical methods. New York: Springer-Verlag.

Royle, D. J., Shaw, M. W., \& Cook, R. J. (1986). Patterns of development of Septoria nodorum and S. tritici in some winter wheat crops in Western Europe, 1981-83. Plant Pathology, 35(4), 466-476.

Russenes, A., Åssveen, M., Bjerke, O., \& Weiseth, L. (2019). Sorter og sortsprøving 2018. NIBIO BOK, 5(1), 28-62.

Saarikko, R. A., \& Carter, T. R. (1996). Phenological development in spring cereals: Response to temperature and photoperiod under northern conditions. European Journal of Agronomy, $5,59-70$.

Shaner, G. (2010). Septoria tritici Blotch. In W. W. Bockus, R. L. Bowden, R. M. Hunger, W. L. Morrill, T. D. Murray, \& R. W. Smiley (Eds.), Compendium of Wheat Diseases and Pests (3rd ed., pp. 56-58). MN: APS Press, St. Paul.

Shaw, M. W., \& Royle, D. J. (1993). Factors determining the severity of epidemics of Mycosphaerella graminicola (Septoria tritici) on winter wheat in the UK. Plant Pathology, 42(6), 882-899.

Shaykewich, C. F. (1995). An appraisal of cereal crop phenology modelling. Canadian Journal of Plant Science, 75, 329-341.

Shearer, B. L., \& Zadoks, J. C. (1972). The latent period of Septoria nodorum in wheat. 1 . The effect of temperature and moisture treatments under controlled conditions. Netherlands Journal of Plant Pathology, 78(6), 231-241.
Shipton, W. A., Boyd, W. R. J., Rosielle, A. A., \& Shearer, B. I. (1971). The common Septoria diseases of wheat. The Botanical Review, 37(2), 231-262.

Simpson, G. M. (1968). Association between grain yield per plant and photosynthetic area above the flag-leaf node in wheat. Canadian Journal of Plant Science, 48(3), 253-260.

Suffert, F., Sache, I., \& Lannou, C. (2011). Early stages of septoria tritici blotch epidemics of winter wheat: Build-up, overseasoning, and release of primary inoculum. Plant Pathology, 60(2), 166-177.

Te Beest, D. E., Pavrley, N. D., Shaw, M. W., \& van den Bosch, F. (2009). Disease-weather relationships for powdery mildew and yellow Rus on winter wheat. Phytopathology, 98(5), 609-617.

Tyldesley, J. B., \& Thompson, N. (1980). Forecasting Septoria nodorum on winter wheat in England and Wales. Plant Pathology, 29, 9-20.

Wainshilbaum, S. J., \& Lipps, P. E. (1991). Effect of temperature and growth stage of wheat on development of leaf and glume blotch caused by Septoria tritici and S. nodorum. Plant Disease, 75, 993-998.

Wang, E., \& Engel, T. (1998). Simulation of Phenological development of wheat crops. Agricultural Systems, 58(1), 1-24.

Wiik, L., \& Ewaldz, T. (2009). Impact of temperature and precipitation on yield and plant diseases of winter wheat in southern Sweden 1983-2007. Crop Protection, 28(11), 952-962.

Wiik, L.,\& Rosenqvist, H. (2010). The economics of fungicide use in winter wheat in southern Sweden. Crop Protection, 29(1), 11-19.

Wright, K. H., \& Sutton, J. C. (1990). Inoculum of Pyrenophora tritici-repentis in relation to epidemics of tan spot of winter wheat in Ontario. Canadian Journal of Plant Pathology, 12(2), 149-157.

Yan, W., \& Wallace, D. H. (1998). Simulation and prediction of plant phenology for five crops based on photoperiod $\mathrm{x}$ temperature interactions. Annals of Botany, 81, 705-716.

Zadoks, J. C., Chang, T. T., \& Konzak, C. F. (1974). A decimal code for the growth stages of cereals. Weed Research, 14, 415-421. 